\title{
"SÓ MASCULINOS, BICHAS ABSTENHAM-SE" O GRINDR COMO ESPAÇO DE (RE)PRODUÇÃO DA HOMONORMATIVIDADE
}

\author{
"ONLY MASC, QUEERS, GET OFF!" \\ GRINDR AS A SPACE OF HOMONORMATIVITY \\ (RE)PRODUCTION
}

\author{
Hugo Santos \\ Centro de Investigação e Intervenção Educativas, Faculdade de Psicologia e de Ciências da Educação, \\ Universidade do Porto. Rua Alfredo Allen, 4200-135 Porto, Portugal. Email: hugosantos@fpce.up.pt
}

\begin{abstract}
Resumo: Alicerçada numa pesquisa de cariz etnográfico multiespacial que envolveu entrevistas semidiretivas de cariz biográfico com 32 jovens rapazes não-heterossexuais, conversas informais e uma componente de etnografia digital com análise de screenshots, foca-se aqui o grindr como um dispositivo de estabelecimento de conhecimentos entre jovens LGBTI, estruturalmente condicionados pela heteronormatividade homofóbica da esfera pública. Verifica-se que o grindr é bastante utilizado por grupos destes rapazes para estabelecer relações de sociabilidade, sendo-lhe atribuído conotações mistas de "liberdade" e de "opressão". As críticas de jovens à aplicação, geralmente assentam i) na tensão moral com o exercício da sexualidade (e.g., a frequência de relações sexuais e o slutshaming); ii) no repúdio abjeto a identidades gays efeminadas ("só masculinos, bichas abstenham-se"); iii) na valorização excessiva de corpos idealizados e, por extensão, bullying direto ou indireto à audiências imaginadas de sujeitos não fisicamente atraentes (bodyshaming), e iv) nos conflitos criados pelo uso indevido da imagem através de perfis fakes (stalking).
\end{abstract}

Palavras-chave: género, gay, cultura, grindr, sociabilidade.

\begin{abstract}
Based on a multispacial ethnographic research that involved biographical semidirectional interviews with 32 young non-heterosexual boys, informal conversations and a digital ethnography with screenshot analysis, we focus on grindr as a device for establishing knowledge among LGBTI young, structurally conditioned by the homophobic heteronormativity of the public sphere. It appears that the grindr is widely used by these youth groups to establish sociability relations, with mixed connotations of "freedom" and "oppression". Young people's criticisms of the application are generally based on i) a moral tension with the exercise of sexuality (e.g., the frequency of sexual relations and slutshaming); ii) the abject rejection of effeminate gay identities ("male only, queers, get off!"); iii) the excessive valuation of idealized bodies and, by extension, direct or indirect bullying to imagined audiences of subjects that are not physically attractive (bodyshaming), and iv) conflicts created by an improper use of image through faking profiles (stalking).
\end{abstract}

Keywords: gender, gay, culture, grindr, sociability.

\section{Introdução ${ }^{1}$}

Criado pelo americano Joel Simkhal, o grindr é uma aplicação utilizada sobretudo em smartphones, disponível para diferentes sistemas operativos, inicialmente 
pensada para rapazes e homens cisgénero que gostam de homens - hoje integra outras possibilidades identitárias como pessoas transgénero - , permitindo assim diversas interações entre eles, nomeadamente íntimas e sexuais (Maia \& Bianchi, 2008).

Com duas versões disponíveis - uma gratuita e outra paga (Grindr Xtra) - , uma das suas particularidades distintivas, por comparação a outras apps, é o uso da geolocalização o que permite detetar a distância aproximada entre perfis, de forma visível ou camuflada, e, desse modo, facilitar encontros reais. Embora outras apps tenham surgido nos últimos anos (e.g., Scruff), a popularidade mundial do grindr parece ser imbatível, não chegando as polémicas sobre a exposição da localização para a colocar em causa (Cover, 2012; Gonçalves, 2017; Maia \& Bianchi, 2008)22.

Na senda de um conjunto de pesquisas emergentes recentes sobre a relação de pessoas e grupos LGBT com as "suas" culturas e comunidades (cf. Ahlm, 2016; Formby, 2017; Gonçalves, 2017; Maia \& Bianchi, 2008; Miskolci, $2013,2015)$, discuto aqui a relação de rapazes não-heterossexuais com o universo online dos dispositivos de "engate", procurando integrar nessa discussão aspetos mais gerais sobre as suas culturas. Esta discussão insere-se dentro de uma pesquisa etnográfica mais vasta sobre culturas juvenis de rapazes gays e bissexuais, levada a cabo entre 2012 e 2013, em diversos espaços da cidade do Porto, onde procurei perceber as relações de pertença e despertença, identificação e desidentificação à espaços tidos como LGBT, de jovens a diferentes tipos de espaços rotulados e amplamente reconhecidos como "gays" ou "LGBT", a que os jovens, muitas vezes, atribuíam termos como "meios" ou "ambientes" (Menezes, 2000; Valentine \& Skelton, 2003), inclusive os virtuais, que são os menos explorados.

Queria conhecer e aprofundar a microfísica das suas sociabilidades e lazeres, ajudando a decifrar o que é comum e distintivo face às culturas juvenis como um todo, ao mesmo tempo que mapeava os sentidos atribuídos a cada um desses espaços pelos jovens, a nível descritivo e lúdico, mas com implicações potencialmente políticas, no postulado que estas culturas e comunidades são como muitas culturas de jovens "formas de reivindicação de uma existência nem sempre objecto de reconhecimento social" (Pais, 2005, p. 63).

A etnografia adquiriu um caráter multisituado onde, mais do que a permanência num só espaço fechado, foi importante observar as relações entre diferentes tipos de espaços, e as formas, consensuais ou contraditórias, como diferentes grupos de jovens se iam apropriando ou desapropriando de cada um desses locais (Valentine \& Skelton, 2003). Posteriormente, a ingressão etnográfica passou a assumir 
contornos "netnográficos" (Maia \& Bianchi, 2008), "visuais" (Pink, 2013), “digitais" (Ahlm, 2016), e passei a investigar territórios online simultaneamente.

Dito de um modo mais conciso, comecei a pesquisa ao contactar uma associação dirigida à população LGBT onde permaneci durante três meses, com visitas semanais (a "Associação Arco-Íris"). Lá acabei por me envolver nalgumas das suas atividades - servir cafés, escrita de relatórios - , o que me levou a aprofundar relações de confiança com um grupo de jovens ligados, diretamente, à Direção. Depois, verificado que a afluência de jovens era escassa, acompanhei outros grupos de jovens que frequentavam sobretudo outros espaços menos formais, como um café, que não sendo propriamente dirigido a este grupo, passa a sê-lo a partir da frequência das pessoas ("Café Dourado"), e um bar ("O Bar do Orgulho"), locais que passaram a constituir-se como alvo da minha atenção e observação e onde, aliás, outras formas de engajamento e participação eram notórias.

Por fim, dado a presença forte dos meios virtuais neste grupo de jovens, comecei a interessar-me pelo papel dos espaços online, passando a estudá-los com mais profundidade, o que significou i) indagar o grupo de jovens com quem andava sobre o seu significado, e ii) eu próprio frequentar esses espaços como investigador.

Nos últimos anos, as novas tecnologias têm desempenhado um papel relevante nos modos através dos quais se vivencia e experimenta novas e velhas possibilidades (e impossibilidades) de género e sexualidade. A massificação da internet e o aparecimento de novas apps de encontros online vieram a criar e recriar "novas" formas de viver cidadanias íntimas, afetivas e sexuais, não só de jovens como de pessoas adultas (e idosas), em que, se ao mesmo tempo, não vieram a inventar nada de verdadeiramente novo no domínio da intimidade e da sexualidade, vieram, pelo menos, a dotar de novas expressões as condições da sua manifestação.

Isto é particularmente relevante para identidades, grupos, comunidades e populações cujas expressões das sexualidades são, de diversos modos, impossibilitadas de uma maior expressão pública, como é o caso das pessoas LGBT que, dada a prevalecente heteronormatividade social em diferentes contextos, ainda tem que exercer as diferentes dinâmicas através de espaços protegidos pelo anonimato (Pullen \& Cooper, 2010).

Não admira o sucesso que, dentro da população LGBT, a aplicação grindr tenha assumido nos últimos anos, o que é particularmente vantajoso para jovens que se encontram num processo de identificação e desidentificação sexual (Gonçalves, 2017; Miskolci, 2015). Mas se ao mesmo tempo estas tecnologias, pelo seu anonimato, se convertem em dispositivos de exploração e experimentação das identidades de cada sujeito (e.g., apresentando-se com um nome falso e simultaneamente estabelecendo conversas com outros sujeitos), ao mesmo tempo, 
também trazem novos processos excludentes para dentro das comunidades, fazendo os usuários terem a noção da rejeição. Neste artigo, exploro os processos excludentes que tecnologias como a rede geossocial grindr oferecem às identidades e populações não-heterossexuais masculinas, reconhecendo que não são aliás apanágio das tecnologias em si, mas sim um reflexo mais vasto de algumas dinâmicas da(s) homossexualidade(s) masculinas per si que são importantes trazer a debate para o fortalecimento da democracia digital.

\section{Enquadramento teórico}

Esta pesquisa não obedece a nenhuma perspetiva ou modelo teórico pré-determinado, mas convoca e integra vários olhares científicos e multidisciplinares na construção do seu objeto que gravita em torno das culturas juvenis de rapazes não-heterossexuais. Esteve na sua base a necessidade de cobrir uma flagrante ausência da literatura académica, sobretudo em Portugal, sobre aquilo que vulgarmente se convencionou chamar "cultura gay", particularmente nos estudos sobre as "culturas juvenis" (Menezes, 2000) que dada a sua heteronormatividade (Huq, 2006) esquece de abordar aspetos relativos à sexualidade.

O facto de ser a Psicologia a produzir mais sobre juventude (ou "adolescência") LGBT, e dado a sua abordagem mainstream centrada em aspetos psicodesenvolvimentais, produziu-se um modo de estudar os/as jovens LGBT mais centrado nas suas identificações individuais e menos naquilo que são as suas práticas culturais. Trata-se de um olhar hegemónico pouco acolhedor da ideia da juventude LGBT como produtora e reprodutora de cultura (Driver, 2008; Filax, 2006; Halberstam, 2005; Miceli, 2002). Assomam-se ao enviesamento deste olhar as críticas relativas a um suposto essencialismo, estereotipia e caricatura sobre a noção de "cultura gay", aos mais diferentes níveis (inclusive, de uma certa respeitabilidade homonormativa), trazidas pelas teorias pós-identitárias, o que obriga os/as investigadores/as a não a abordar como tal.

Ora, os próprios estudos sobre cultura gay têm-se confinado a um olhar adultocêntrico, o que se pode dever ao facto de serem os homossexuais adultos aqueles que estabelecem os padrões legítimos do ativismo e da investigação (Halberstam, 2005). Se por "cultura" entende-se um conjunto articulado de ideias, comportamentos e práticas não-naturais, materiais, simbólicas ou imaginadas, que membros tidos dessa cultura, operam num determinado espaço-tempo (Geertz, 1993; Pais, 2005), e se por "culturas juvenis" se quer referir "às experiências juvenis, às produções biográficas e identitárias que jovens realizam perante um mundo sobre o qual têm um domínio relativo" (Silva, 2011, p. 18), as culturas juvenis 
não-heterossexuais são simplesmente aquelas que são produzidas por sujeitos jovens não-heterossexuais, e que se caraterizam pela "partilha de níveis de significado particulares e por um estilo de vida que corresponde, mais do que a uma experiência homossexual, a uma vivência identitária traduzida na expressão 'ser gay'" (Menezes, 2000, p. 937), nunca se ignorando o facto de também se incluir nela aqueles que não se reconhecem como seus membros, dado que ela parece funcionar como o seu elemento fantasmático ("os fora do meio") (Gonçalves, 2017; Miskolci, 2013, 2015).

A operacionalização do conceito de "cultura gay" não anula a sua complexidade, cruzando-se estes com outros como, por exemplo, "comunidade gay", um conceito igualmente problematizável por implicar um conjunto diverso de definições. A esse propósito Eleanor Formby (2017) explica que existem cinco sentidos para "comunidade LGBT": i) a comunidade como um território espacializado (a ideia de um "gueto gay"); ii) a comunidade como um lugar de práticas culturais e materiais que se produzem; iii) a comunidade como entidade "imaginada" (ou "imaginário gay"); iv) a comunidade como um lugar de interações e relações interpessoais, de sociabilidade e de amizade e, por último, v) as comunidades virtuais e cibernéticas, e todas estas noções de "comunidades" são importantes para se (re)pensar as "culturas juvenis", e particularmente as culturas gays.

As culturas não são nada sem os sujeitos que as dotam de significado e uma das razões desta opção por uma abordagem etnográfica é restituir a importância da agência de jovens homo e bissexuais, subsumida numa boa parte da literatura, sobretudo psicológica, que os tem produzido mais pelo prisma narrativo das vítimas passivas do que pelo poder da agência em toda a sua complexidade (Cover, 2012). Como refere Miceli, "se nós virmos esta população como um grupo lutando com a sua identidade estigmatizada, então estamos a perder aspetos cruciais do conhecimento sociológico." (Miceli, 2002, p. 204)3.

\section{Metodologia}

Iniciei esta etnografia sobre culturas juvenis numa associação especificamente dirigida à população LGBT do Porto, querendo saber a relação dos jovens com ela. Cedo descubro que a associação falha em captar os jovens, em parte, dado o seu formalismo homonormativo - como vão reconhecendo os jovens, por outras palavras - , e começo, com grupos de jovens distintos, a descobrir novos lugares da sua preferência - os cafés, e um café em particular a que dei o nome de "Café Dourado", um bar, aberto somente aos fins-de-semana, e a rua, que acabou por ser um 
contexto de interpelação - , o que me leva a indagar sobre o "caráter constelar" (Chisholm, 2005) da ou destas culturas juvenis.

Ao longo da pesquisa foram-se envolvendo vários jovens, mas existem três grupos principais com os quais passei mais tempo e interagi mais: i) os jovens da associação; ii) os jovens do café e dos bares; e iii) os jovens do online. Cheguei a este último grupo (e fase da pesquisa), a partir do contacto com os grupos anteriores, sendo introduzido ao mundo do grindr e aos significados e relações que, a partir dele, se estruturam e desestruturam ${ }^{4}$.

O grindr foi interpelado nesta pesquisa a dois níveis principais: na relação e sentidos atribuídos pelos jovens ao mesmo, patentes em observações, escrita de notas de terreno e entrevistas semiestruturadas, e, posteriormente, no universo interior do online propriamente dito, onde submergi como "etnógrafo digital" (Ahlm, 2016). Nesta incursão online, para uma imersão completa dos dados, e considerando a importância de uma total implicação do investigador (Rooke, 2010; Silva, 2011), criei eu próprio um perfil no grindr, com uma foto de rosto visível minha, e preenchi alguns detalhes, mais ou menos "neutros", como altura, estado civil e sexo. Á medida em que andava com os jovens através de espaços offline, estava com o grindr ligado e ia conversando com outros perfis. Uma vez lá fui analisando i) textos de perfis eii) conversas que ia tendo com perfis, tirando print dos screenshots de ambos. Os dados desta pesquisa fundamentam-se pois na observação participante e entrevistas semiestruturadas aos 32 jovens com quem andava na minha pesquisa offline, nas muitas conversas informais que fui tendo com perfis no próprio grindr, onde me "loguei", pelo menos, uma vez por dia, durante quatro meses de interação, alguns deles consubstancializando-se em encontros reais posteriormente. Todos estes modos de uso do grindr foram essenciais para produzir uma "descrição densa" (Geertz, 1993) sobre as interações.

Como recorda Baker (2013), a internet é um lugar contestado em que qualquer pesquisa necessita de ter em mente as potenciais diferenças ontológicas entre mundos offe online. Fazer pesquisa com recurso a conversas no grindr exige uma reconceptualização das dinâmicas ontológicas, metodológicas e éticas tradicionais de pesquisa. Uma das primeiras interrogações foi precisamente sobre o que constitui terreno. Numa pesquisa online, o terreno tende a apresentar limites fronteiriços mais esbatidos, indo ao encontro daquilo que alguns/mas denominam de "terreno expandido" (Hammersley \& Atkinson, 2007). Se se considerar a influência dos sentidos dos diferentes grupos de jovens sobre o próprio grindr, isso torna-se particularmente evidente nesta pesquisa de cariz variado em que o terreno é também uma construção psicológica e emocional (Rooke, 2010).

Uma outra dimensão a conceptualizar no universo online foi a ética. Reparei que sempre que criava um texto a apresentar-me como investigador e a explicar 
sucintamente a pesquisa na caixa de texto disponível da app, o grindr bloqueava o meu perfil, daí que o consentimento informado era negociado através de conversas "privadas" com outros perfis, e dessas conversas era feito um printscreen/screenshot. Por razões éticas, fazia print, com consentimento, a esse mesmo texto de apresentação e consentimento que, em certos casos, gerava novos bloqueios, pois, muitas pessoas tinham medo de ser expostas (ainda que não apresentassem dados nenhuns sobre si). É importante dizer que desses screenshots toda a informação relativa à fotografia do indivíduo, informações pessoais dos sujeitos ou localização, era apagada, mesmo que se considerasse a possibilidade de ser falsa. Os nomes utilizados são pseudónimos.

Quer os corpos de textos apresentados, quer as conversas privadas respetivas, eram sujeitas a print e analisadas tematicamente, constituindo-se como dados. Como se trata de uma amostragem da população não probabilística, assume-se que na escolha dos screenshoots objeto de análise teve-se uma seleção cujo critério principal era a sua adequação ao objeto da pesquisa. Foram "printados" 200 screenshoots e perfis, tendo ou não uma relação entre si. Constituem como "dados" também as conversas com os jovens (muitas delas envolvendo a sua relação com o dispositivo), o que representa um dado rico e esclarecedor na medida em que são os seus sentidos, e não os meus. As entrevistas foram também objeto de análise com recurso à análise temática (Braun \& Clarke, 2006). Um dos temas das entrevistas foi precisamente "identidades e dinâmicas sexuais" que dizia respeito aos modos como os jovens viviam e expressavam a sua sexualidade. Um dos subtemas ("media digital") dizia respeito à relação com os meios digitais entre os quais o grindr. É importante realçar que as entrevistas eram de cariz biográfico pois abarcavam um conjunto de dimensões da vida dos jovens e não estavam centradas na sexualidade apenas.

É importante salientar que os jovens do grindr, podem não ser propriamente jovens na medida em que cada perfil pode ser simulado, assim como é importante esclarecer que, embora os limites caraterizadores da juventude obedeçam a critérios de natureza contingente ou conveniência sociopolítica (Bourdieu, 1992), define-se, nesta pesquisa, como "jovens" os indivíduos cuja faixa etária se localiza entre os 16 e os 24. Existem linhas bastante ténues entre o investigador e a sua pesquisa. Camilo Braz (2012) reflete sobre como, enquanto homem gay, as tensões eróticas entre si e os participantes eram frequentes, algo que aconteceu nesta pesquisa, mas contribuiu, sem dúvida, para um melhor conhecimento sobre o funcionamento do dinamismo afetivo do grindr (Rooke, 2010). 


\begin{tabular}{ll}
\hline Tema - Aspetos positivos do grindr & \\
\hline Subtemas - Relações interpessoais & Subtemas - Comunidade \\
Conhecimentos & Apoio \\
Sociabilidade & Sentido de pertença \\
Amizade & Consciência política \\
\hline Tema - Aspetos negativos do grindr & \\
\hline Subtema - Fatores de exclusão & Subtema - Perigosidade online \\
Género & Slutshaming \\
Aparência física & Porn revenge \\
Idade & Blind date \\
\hline
\end{tabular}

\section{Resultados}

"É fixe porque podes conhecer outras pessoas, pessoas que gostam do mesmo que tu, com a mesma orientação sexual, mas, por outro lado, também te podes dar mal, podes ser excluído, por seres isto ou aquilo". É desta forma que Leandro, um rapaz de 20 anos, estudante, descreve em entrevista a sua relação com os sites e apps de encontros afetivos e sexuais online voltada para um público masculino não-heterossexual, e, neste caso específico, com o grindr, uma app bastante popular entre homens que gostam de homens, gays ou bissexuais, de todo mundo, cuja caraterística distintiva face a outras apps (como o Tinder, por exemplo), é a possibilidade de usar a geolocalização dos usuários, com a sua permissão (Maia \& Bianchi, 2008) 5 .

O que o Leandro destaca, de modo semelhante a outros participantes da pesquisa, é este paradoxo entre, por um lado, a gratificação obtida com o estabelecimento de afetos, sociabilidade, amizades e laços comunitários, que os espaços online, de modo geral, permitem através do encontro (anonimizado) entre pessoas com identidades não-heterossexuais (necessariamente separadas, na maior parte dos casos, pela estatística, geografia e heteronormatividade social) (Luzia de Abreu, 2012), mas, ao mesmo tempo, a sua constituição como espaços em que o sujeito se depara com novos processos internos de discriminação e de violência que tanto recordam a homofobia social (Valentine \& Skelton, 2003).

"O que procuras?"

Decorrente da sua imagética e design, pode-se assumir que o grindr é uma app fortemente sexualizada. Os perfis consistem numa fotografia, num espaço de texto livre, personalizável e limitado a certos carateres, contém informações pré-definidas 
como idade, altura, peso, tipo de corpo, estado de relacionamento ou etnicidade, e existe a possibilidade de várias combinações, ou de simplesmente não se responder a nada. Em todo o caso, o grindr parece não escapar de um certo apelo homoerótico patente na exibição de muitas fotografias de perfil com corpos desnudados ou em poses sensuais, focando, ora um corpo inteiro com o rosto da pessoa, ora certas partes do corpo como bíceps ou abdominais, contribuindo para a sua faceta fortemente sexualizada (Ahlm, 2016).

Contudo, os sujeitos vão utilizando o grindr de diferentes formas. Os jovens com quem fui conversando através do sistema de mensagens, fora e dentro do grindr, apresentam um conjunto diverso de razões para o seu uso, quer nos textos escritos nos seus perfis, quer nas razões apresentadas em conversas, podendo ou não convergir entre si. Há aqueles que procuram simplesmente "conhecer alguém e fazer amizade" - neste caso, o "tomar café" aparece como uma metáfora poderosa para o efeito -, aqueles que procuram um relacionamento tido como "sério" (monogâmico), e aqueles que procuram apenas "uma curte". Essas intenções podem, inclusive, variar ao longo do tempo, a curto (no próprio dia) ou longo prazo (ao longo dos anos), como explica o Leandro: “Depende muito. Depende muito do momento! Às vezes estás numa de conhecer apenas, outras vezes, queres apenas pinar!" (Entrevista a Leandro).

Uns tendem a usar o dispositivo com o objetivo de manter conversas que só ali ocorrem, outros usam-no como um meio seletivo para manter interações privadas noutro dispositivo ou lugar (e.g., WhatsApp), e outros ainda o usam como meio direto para um encontro no real imediato, sendo a expressão "real" usada de modo frequente, sobretudo para se referir a "sexo". Na verdade, das fotos desnudadas e erotizadas, aos textos e símbolos/emojis - como de uma beringela para pénis - , o grindr parece invocar um imaginário hipersexualizado, que é difícil ignorar. A clarificação daquilo que se procura é um momento-chave no grindr e é verificável a partir dos teores das conversas. Da análise dos screenshots, verifica-se uma estrutura-tipo de conversa que vêm sob a seguinte forma:

- “Olá, tudo bem?

- Tudo, e contigo?

- Tudo [smile]

$-\quad$ smile $]$

- O que procuras?"

A resposta é variável, mas não deixa de ser curioso uma certa nebulosidade sobre o que se procura em concreto, com alguns a comentarem "Eu uso isto apenas para 
passar o tempo, para ver quem está e quem não está" [screenshot160] e "o meu objetivo é conhecer simplesmente". "Conhecer e ver o que surge..." [screenshot086]. Contudo, não deixa de ser interessante como a revelação do que verdadeiramente se procura fique sujeito a um determinado tipo de inflexões estratégicas e performativas. A resposta àquilo que se procura, é amparada por um conjunto de antecipações e proteções que se faz em relação aos "verdadeiros" desejos, sendo as diferentes manifestações expressas, segundo determinadas convenções sociais porque "há muita gente que diz que procura amizade e vai-se a ver só procura sexo, mas diz que procura amizade só para parecer bem..." (Entrevista a Luís).

O tipo de fotografia exibida, à partida, pode indicar o que se procura, mas também era possível verificar que certos indivíduos expressavam intenções totalmente opostas. Não era incomum indivíduos com textos de perfil fortemente erotizados, dizerem que procuram amizade, ou o contrário: dizerem que "procuram amizade, e a primeira coisa que mandam são nudes" [screenshots091]. Estas discrepâncias, estes jogos de espelhos (Menezes, 2000), revelam a tensão existente entre o ser-se abertamente sexual e as consequências que daí derivam para as impressões sociais circundantes, mesmo - e talvez porque - num meio particular.

O que parece ser claro é que muitas das expressões ou não-expressões de identificações ou desejos obedecem a jogos estratégicos de gestão da autoimagem, sendo isso patente na luta compulsiva de troca privada de fotos para ver o rosto de outrem e esconder o seu. É isso que torna as "discrições" e "os pedidos de sigilo" tão invocados, e tal não se deve apenas ao caráter heterossexista e homofóbico do meio uma vez que, à partida, o grindr é frequentado maioritariamente por não-heterossexuais, mas sim à gestão da autoimagem para outros semelhantes, como se diversas relações de poder operassem entre diferentes grupos e tipos de homens gays e bis (Miskolci, 2015).

Ao contrário de uma certa estereotipia sobre uma alegada "promiscuidade gay" (sem o peso cultural semelhante para a heterossexualidade masculina, dado o duplo padrão sexual penalizador para mulheres e homens não-heterosexuais), é verdade que não deixa de haver equacionamentos morais e éticos sobre a sexualidade. Uma análise mais aprofundada permite verificar algumas tensões entre aqueles que procuram conhecer simplesmente, e aqueles que procuram simplesmente sexo. Nesse campo, é importante destacar que o slutshaming, i.e., vigiar e regular a frequência das práticas afetivas-sexuais com recursos a expressões estigmatizantes (e.g., "puta"), e relacionadas com o vírus do HIV, parece ser bastante comum fora e dentro dos espaços online, embora, simultaneamente, esse slutshaming pareça ser mais performativo do que autêntico. Como explica um dos jovens na entrevista: "Benny: - Fazem isso a todos. Chamam puta até como um elogio. É como bitch. E 
para eles todos são umas putas. Puta é quem teve mais sexo que tu. É puta!" (Nota de Terreno, Café Dourado, junho de 2012).

Se, por um lado, existe uma forte hipersexualização, por outro lado, também existe uma forte regulação moral da sexualidade que deve ser compreendida em termos estritamente culturais. Como explica o David em tom confessional:

Tu até podes procurar conhecer alguém, na desportiva, só para tomar um café, conhecer, mas tu sabes que ninguém procura aquilo e vai passando e tu tens desejos, né? Chega um ponto em tu que já não queres saber, é para foder, é para foder! Aquilo é tão [faz uma cara de nojo] que acabas por te entregar... (Entrevista cara a cara a David).

Existe uma maior complexidade na gestão daquilo que se procura entre diferentes indivíduos que não se pode reduzir às categorias dicotomizadas entre "santa" e "puta" que, como referiu o Leandro, "somos um pouquinho de cada" (Entrevista a Leandro). Dito de um modo sucinto, aquilo que se procura é mais complexo do que, à partida, o senso comum (heterossexual) pode julgar. Como refere Miskolci (2015), sujeitos gays e bis são regidos por padrões culturais de sexualidade semelhante.

\section{Capital erótico, hierarquias de desejabilidade e exclusões}

É a partir deste postulado do "desejo" e "poder" que o grindr se converte num espaço profundamente excludente. Essa exclusão atua a diferentes níveis, mas a linha central é a extrema homonormatividade, expressa por muitos sujeitos, que é notória nos textos e nas conversas. Uma das dimensões mais evidentes é ao nível da expressão (e identidade) de género. Nos textos de perfil, e conversas, onde declarações como "só masculinos, bichas abstenham-se", "pulsos partidos não" ou "bloqueio efeminados" aparecem, parece ser claro as exigências de hipermasculinidade que são solicitadas. Cover (2012) identifica como uma das 5 formas de homonormatividade na cultura gay a (in)conformidade de género.

É comum o uso discursivo da categoria de "bicha" como um divisor de aceitabilidade das homossexualidades. A "bicha" aparece aqui como uma identidade fantasmática e excluída a partir do qual os próprios corpos gays masculinos têm que se ser reequacionados. A este respeito, André Gonçalves (2017) constata que a discrição heteronormativa é bastante invocada e cumpre o propósito não só de não colapsar aquilo que ele chama de "audiências imaginadas" como também de provocar um imaginário homoerótico que se sustenta na valorização da masculinidade hegemónica. "Procuro gajos masculinos como eu. Nada de efeminados e aves raras. Se quiser estar com uma mulher, procurava uma. Só gente discreta". [screenshot23] 
Existem muitas possibilidades de interpretação e leitura desta "bichafobia". Por um lado, insere-se certamente dentro dos compreensíveis quadros de preferências eróticas, com uma clara valorização da masculinidade hegemónica, eixo gravitacional das formas dominantes de homoerotismo; por outro lado, deve-se fundamentalmente à preservação de uma certa "discrição" no qual certos grupos de homens não-heterossexuais são mestres-declarados. É por isso que, em certas ocasiões, assiste-se a anúncios de perfis que se intitulam como "heteros" ou "bis com namorada" exigindo "sigilo absoluto" e, em certos casos, sugerem "fazer [sexo] e esquecer", como o observado em outras pesquisas (cf. Miskolci, 2013, 2015). É o caso do Alex que me confidencia numa conversa, antes de me bloquear: "Não estou cá para merdas. Queres, tudo bem, não queres, caga. Não mando foto de cara. Sou discreto, tenho uma relação, não quero chatices! Xau aí" [screenshoot14].

Esta "discrição", porém, tem que ser lida em termos profundamente performativos na medida em que os sujeitos não deixam de efetuar um certo roleplay sobre essa personagem do "discreto" e do "hetero", com claras vantagens em termos de obtenção de um parceiro, num movimento centrífugo que mais parece recopiar uma competição erótica (Ahlm, 2016). Um dos sujeitos explica-me que a discrição tem um subtexto homoerótico: "Nélson: - Se quiseres conhecer um gajo tens que ser discreto porque assim afastas bué o pessoal..." [screenshot27].

Em todo o caso, esta valorização da hipermasculinidade, e consequente rebaixamento do homem gay ou bi não-masculino e, sobretudo, efeminado, manda uma mensagem simbólica a homens gays e bissexuais efeminados que aquele não é nem deve ser o seu espaço. Esta aversão a sujeitos efeminados, ao revelar uma clara preferência erótica pela masculinidade hegemónica, manda uma mensagem simbólica a sujeitos queer que não são bem-vindos, que o seu acesso ao sexo deve ser vedado assim como as suas cidadanias íntimas e sexuais.

Uma outra dimensão excludente e elitista tem a ver com as exigências com o formato corporal. Muito se escreveu sobre a cultura fit de homens gays, a idealização e reificação do corpo tonificado que atua como um cliché alternativo, quase paradoxal, ao estereótipo do homem efeminado, e como um guia orientador para muitos jovens que encontram estas imagens antes de conhecer uma pessoa LGBT (assumida). No grindr, esta obsessão pelo corpo tonificado era observável em muitos perfis, com solicitações várias em direção a corpos "musculados" e "gente que se cuide", e este cuidado não se reduzia a um mero cuidado de saúde, mas sim, era levado ao extremo.

Mas também como no género, em que não basta ser masculino, é preciso não ser bicha (o excedente), aqui não só corpos tonificados eram apreciados ("fit apenas"; "musculados como eu"), como, na sua extensão inversamente proporcional, 
também corpos gordos eram explicitamente indesejados, repudiados, tornados abjetos, com comentários como "gordos não" ou "tenham noção, não quero potes de banhas!". Esse bodyshaming gordofóbico tanto pode ser expresso nos textos dos perfis como diretamente enunciado pelos usuários. Numa das minhas aproximações, um dos jovens refere: "não falo com gordos", e bloqueia-me. Nas entrevistas, os jovens vão revelando como sofreram diversas situações constrangedoras no grindr como, por exemplo, cyberbullying, pelo facto de serem "gordinhos". Esta relação com o corpo exclui, desde logo, aqueles cujos corpos não se inserem dentro do registo de capacidade hegemónica como é o caso das pessoas com incapacidade ou deficiência (Cover, 2012).

Mais uma vez, se revela como para os/as jovens LGBT gordos/as a possibilidade de acederem a redes de apoio e suporte via online, pode ser mais difícil. Por fim, o idadismo também tende a ser bastante comum neste dispositivo. Em muitos textos, é comum solicitarem-se indivíduos mais jovens traçando-se limites particulares cujas fronteiras máximas, salvo raras exceções gravitam em torno de três franjas principais: os 20; os 24 e os 30. Este idadismo é, na verdade, um substrato das exigências do corpo fit e, não sendo um exclusivo da cultura gay, adquire aqui uma particularidade opressiva se se considerar a estrutura comum das relações homossexuais e a solidão na terceira idade (Halberstam, 2005). Este idadismo torna-se então mais pronunciado nestes contextos online, e torna-se cada vez um divisor moderno das homossexualidades. Como refere J. Halberstam:

\begin{abstract}
Enquanto que no passado, namoros interageracionais queer permitiram a homens e mulheres passar informação, práticas sexuais, e conhecimento histórico de uma geração para a outra, agora a juventude gay "está" protegida das "predações" das pessoas LGBT mais velhas. No passado, dinâmicas edípicas puderam ser evitadas nas comunidades queer porque a divisão entre juventude e pessoas mais velhas era subestimada; agora, a juventude gay pode querer muito suplementar os modelos de identidade das gerações mais velhas, comunidade e ativismo. A "vergonha gay", outra vez, com a sua enfase em aclamar a materialidade abjeta que o "orgulho" descartou, aumentam essas divisões geracionais e permite a jovens gays dirigir a sua raiva a esses/as ativistas lésbicas e gays que tornaram grupos de jovens gays possíveis em primeiro lugar (Halberstam, 2005, p. 222-223) ${ }^{6}$
\end{abstract}

Dito de certo modo, o universo do grindr pode ser pensado à luz das teorizações de Adam Isaiah Green sobre o "capital erótico" e os "campos sexuais" (cf. Green, 2008). Segundo Green, o "capital erótico" refere-se à "qualidade e a quantidade de atributos que um indivíduo possui, que provocam uma resposta erótica em outro" (29), enquanto os "campos sexuais" são espaços dentro dos quais esse capital 
erótico é (re)negociado, dentro de uma constelação de elementos físicos, emocionais, estéticos das identidades. Os campos sexuais são organizados hierarquicamente, a partir das hierarquias de desejabilidade: quanto mais alto na hierarquia se é, mais poder se tem sobre o status sexual e o contato. O ato de "bloquear" (ou "não responder") funciona aqui como um desejo de segregação digital do outro.

\section{Problemas virtuais são problemas reais?}

Como se viu, embora facilitando o acesso a formas de comunidade, intimidade e sexualidade, o grindr apresenta problemas de exclusão que dinamitam possibilidades comunitárias e expõe a extrema vulnerabilidade a que certos grupos de jovens, em detrimento das suas caraterísticas pessoais, ficam expostos (como, por exemplo, cyberbullying entre os seus semelhantes). Todavia, existem perigos associados à aplicação que decorrem da sua natureza iminentemente digital, e que aliás são extensíveis a outros dispositivos online nas mediações com a realidade offline. Uma das situações mencionadas pelos jovens (ainda que não por esse nome) é o catfishing, i.e., pessoas que se fazem "passar" por outras não apenas para se constituírem como "voyeurs digitais" (Luzia de Abreu, 2012, p. 31), mas para arrancar informações pessoais de outrem, com os diversos fins. Os fakes proliferam no grindr servindo muitos deles o propósito de ver quem é quem, como explica o Manuel e o Luís:

Manuel: - Eu tive um gajo que estava a 20 metros de mim! 20 metros!

Hugo: - E o que fizeste?

Manuel: - Andei imenso tempo a tentar perceber quem era, mas nunca consegui, o gajo não respondia.

Luís: - Fácil, fazes um fake e falas com ele como se fosse outra pessoa. O gajo se calhar não fala porque te conhece.

(Nota de Terreno, Café Dourado, dezembro de 2012)

Num contexto contemporâneo de pós-verdade e fake news (cf. Barclay, 2018), a falsificação são um dos perigos mais enunciados. Esta noção de que "nunca se sabe com quem está a falar" é uma das preocupações expressa de muitos jovens que não chega, porém, para travar os encontros que são parte constitutiva destas culturas juvenis. Num dos momentos etnográficos off, um dos rapazes marcou um encontro com outro que estava nas redondezas e decide ir ao seu encontro:

Estou no café com o David, o Pedro e o Luís. O Pedro, fica eufórico e mostra-nos a conversa com o rapaz que está a falar no grindr. Evidencia os abdominais e refere que ele tem "local". O Zé é cauteloso e alerta Pedro. 
Zé: - O problema é que depois tens monte de pessoal a fazer-se passar por quem não é. Usam a foto dos outros...

Hugo [fico intrigado]: - Mas isso é ilegal, certo?

Zé: - É, mas achas que eles se preocupam...?

Pedro: - Ainda fazem pior, se mostrares medo...

Hugo: - E porque fazem isso?

Zé: - Para prejudicar alguém, para exporem, ou...

Pedro: - Ou para sacarem informações sobre alguém...

Hugo: - Como assim?

Pedro: - Para testarem os outros; se calhar é um velho ou um feioso para seduzir outros para ser mais atraente...

Bruno: - É por isso que tenho cuidados com isso! Ninguém é o que parece!

Pedro: - Eu tenho um amigo meu que uma vez combinou um date e foi roubado. Apareceu um gajo com uma naifa e zau, foi roubado. Roubaram o Iphone! Hugo: - E o teu amigo apresentou queixa?

Pedro: - Achas? ‘Olhe senhor guarda, marquei um encontro no grindr e fui gamado por outro gajo'. Uma bicha roubada. O bófia ainda se ria de mim LOL.

(Nota de Terreno, Café Dourado, janeiro de 2013)

Estes medos vão ao encontro de "audiências imaginadas" de que nos fala Gonçalves (2017), de que nunca sabemos quem nos está a ver, ou com quem estamos a falar, podendo ficar sujeitos a diferentes tipos de manipulações. É, por isso, que a troca de redes sociais (como o Facebook ou o Instagram) era solicitada por alguns usuários com o objetivo de, pelo menos, atenuar as desconfianças sobre a identidade verídica de com quem se fala ("insta? tens?" [screenshot, 31]). Nesse seguimento, um outro problema levantado pelo grindr, e discutido pelos jovens, foi o ato de revenge porn, i.e., a difusão de conteúdos pornográficos não consentidos ou autorizado, geralmente com o intuito de vingança, humilhação ou chantagem (sextortion) que não sendo uma novidade dentro dos fenómenos de shaming, adquire a sua massificação com o advento da tecnologia e a crescente facilidade de acesso a meios cada vez mais dissimuláveis para a recolha de imagens. É o caso dos cuidados com as nudes que vão sendo mencionadas pelos sujeitos:

David: - Eu nunca mando. Tenho medo. Há bué de pessoal que usa essas imagens para te expor depois.

Luís: - E? Quero lá saber! Que espalhem...

David: - Não é bem assim, tipo, podes ter problemas com isso, de fotos tuas nuas irem parar na net

Pedro: - Ya, é preciso cuidado. Eu quando mando, mando sempre sem cara.

(Nota de Terreno, Café Dourado, fevereiro de 2013) 
O que é relevante salientar é como é através destas conversas que os jovens vão construindo as suas identificações e subjetificações sexuais, criando temas de conversa, discutindo os aspetos positivos e negativos das questões, aprendendo estratégias de lidar com as redes sociais e dispositivos virtuais, sendo o espaço do Café ideal para o efeito.

\section{Conclusão}

A minha análise do grindr não pretende ser exaustiva nem tampouco pretendi generalizar sobre as experiências de muitos jovens gays ou bis, e usuários da app. Pelo contrário, procurei as que fossem importantes para compreender certos aspetos destas culturas. O que se pode concluir é que o grindr, assim como outros contextos online, é um espaço de exploração e experimentação da afetividade e do homoerotismo que atravessa a cultura gay contemporânea. É um espaço que permite novas e agradáveis conexões, mas, ao mesmo tempo, é um espaço profundamente excludente, com prejuízo para os jovens que estão em processos geralmente difíceis de construção das suas identificações. Essa exclusão é multifacetada, mas três delas são muitos evidentes: a expressão de género, os padrões físicos normativos e a idade.

Quanto à expressão de género, a exclusão dirige-se para aqueles que, aparentemente, não seguem nem querem seguir o formato reconhecível de uma masculinidade normativa ("as bichas"). Aqueles que são identificados desse modo são afastados de qualquer possibilidade de contacto ou amizade, sendo o grindr claramente insuficiente como dispositivo de criação de capital social e solidariedade para sujeitos queer. Em muitos casos, não se trata nem de uma masculinidade normativa, mas sim das suas versões mais radicais e ortodoxas: a hegemónica. No que toca aos padrões normativos, possuir um corpo com excesso de peso torna o sujeito predisposto a diferentes formas de bullying como foi dito e acontecendo com os sujeitos da pesquisa. Há uma valorização constante de um corpo musculado e a rejeição de todos aqueles que não cumprem esse pré-requisito, com repercussões na forma como muitos sujeitos são percebidos. A idade também funciona nesta app como um fator de exclusão, valorizando-se os sujeitos com uma idade reconhecida como "mais nova" e rejeitando-se aqueles que ultrapassam essa fronteira.

Género, corpo e idade, como argumentam Stoer e Magalhães (2005), são três dos grandes fatores de exclusão das sociedades contemporâneas pós-capitalistas pois representam os grandes nichos através dos quais as lógicas do mercado se articulam. Como refere Rob Cover, "o que a cultura queer homonormativa faz, é produzir um conjunto de exclusões que são utilizadas para policiar as fronteiras da 
comunidade queer de forma que pareça plausíveis, desejáveis e rentáveis para uma sociabilidade neoliberal mais vasta" (Cover, 2012, p. 124).

Um outro problema colocado pelo grindr é precisamente o facto de transformar as velhas redes de sociabilidade obsoletas. Num estudo de Ghaziani (2014), o autor reflete de que forma e se, o grindr está a causar, de modo indireto e involuntário, o fechamento de bares e comunidade gays. Contudo, é preciso transpor a ideia fatalista e demonizadora sobre as potencialidades afetivas do online. Significa isto que, em última instância, elas não são excludentes per si, mas são sim um reflexo daquilo que as culturas juvenis gays o são, permitindo, de forma anónima, o expressar sem culpas. Num dos mais belos artigos sobre "cena gay", Gill Valentine e Tracey Skelton (2003) constataram como esta é profundamente paradoxal e antagónica, um lugar que revela novas possibilidades de comunidade, e, simultaneamente, de perigos e marginalizações. É neste limbo que se deve considerar o estatuto do online. A internet pode ter um efeito complementar que passa por flexibilizar a agência e dinamismo político da identidade e comunidade gay. Nesse sentido, como conclui Ghaziani, "adiciona e constrói outras formas de comunicação e comunidade" (Ghaziani, 2014, p. 126), mas também pode ser profundamente perversa, expondo, quase de modo psicanalítico, o nosso pior lado, com prejuízo para os entendimentos democráticos das nossas relações.

\section{Notas}

1 Por decisão pessoal, o autor do texto escreve segundo o novo acordo ortográfico, não por razões políticas, mas por razões formais de uniformidade linguística.

2 Em termos do seu funcionamento, para criar um perfil, o usuário pode fazer download da app e só precisa de uma conta (que pode ser falsa). Depois existe ao dispor um conjunto de opções como colocar uma fotografia pessoal ou preencher detalhes de perfil, pré-definidos e abertos (i.e., texto), ou não colocar absolutamente nada, sendo que muitas destas informações podem ser manipuladas (e.g., a foto pode ser de outra pessoa e pode-se mentir/omitir nos detalhes como, por exemplo, dizer que se tem um peso que não se tem). Ainda que a própria app imponha um conjunto de restrições, como proibir fotos de nudez explícita e possibilite a denúncia de situações inusitadas (e.g., para quem promove discursos de ódio ou usa fotos de outra pessoa), não controla esses possíveis microsimulações de cada um/a.

3 Optou-se, sempre que possível, por traduzir livremente.

4 A opção por uma população gay e bissexual masculina deve-se a vários fatores, entre os quais o fato de estas culturas serem predominantemente masculinas, e ao facto do próprio investigador se assumir como "homem gay", interessando-se expressamente por cultura gay. 
5 É importante referir não só outras apps dirigidas à comunidade LGBT (mais gay do GBT, francamente) como, por exemplo, o Scruff, o Hornet, entre outras, como também apps que, embora não sejam exclusivamente direcionadas para pessoas LGBT, por eles são usadas, assim como por pessoas heterossexuais, como, por exemplo, o Tinder.

6 Tradução livre feita pelo autor, como aliás são todas as traduções presentes no artigo.

\section{Referências}

Ahlm, J. (2016). Respectable promiscuity: Digital cruising in an era of queer liberalism. Sexualities, 20(3) 364-379.

Baker, S. (2013). Conceptualising the use of Facebook in ethnographic research: As tool, as data and as context. Ethnography and Education, 8(2), 131-145.

Barclay, D. A. (2018). Fake news, propaganda, and plain old lies. How to find trustworthy information in the digital age. Nova Iorque: Rowman \& Littlefield.

Bourdieu, P. (Ed.) (1992 [1984]). La 'jeunesse' n'est qu'un mot. Questions de sociologie (pp. 143-154). Paris: Éditions de Minuit, 1984. Disponível em http://www.homme-moderne.org/societe/socio/bourdieu/questions/jeuness.ht $\mathrm{ml}, 30 / 05 / 2013$

Braun, V., \& Clarke, V. (2006). Using thematic analysis in Psychology. Qualitative Research in Psychology, 3(2), 77-10.Braz, C. (2012). A' meia-luz...: Uma etnografia em clubes de sexo masculinos. Goiânia: Editora UFG.

Chisholm, D. (2005). Queer constellations. Subcultural space in the wake of the city. Minneapolis: University of Minnesota Press.

Cover, R. (2012). Queer youth suicide, culture and identity unliveable lives?. Londres: Ashgate.

Driver, S. (2008). Queer youth cultures. Albany: State University of New York Press.

Filax, G. (2006). Queer youth in the province of the "severely normal". Vancouver: UBC Press.

Formby, E. (2017). Exploring LGBT spaces and communities. Contrasting identities, belongings and wellbeing. Nova Iorque: Routledge.

Geertz, C. (1993). Studies in ethnomethodology. Nova Jersey: Prentice-Hall.

Ghaziani, A. (2014). There goes the gayborhood?. Princeton: Princeton University Press.

Gonçalves, A. (2017). A identidade social nas redes sociais "online": A construção de autoapresentações anónimas mediadas pelo "Grindr" (Dissertação de mestrado). Instituto Universitário de Lisboa, ISCTE-IUL, Lisboa.

Green, A. I. (2008). The social organization of desire: The sexual fields approach. Sociological Theory, 26(1), 25-50. doi: 10.1111/j.1467-9558.2008.00317.x

Halberstam, J. (2005). Shame and white gay masculinity. Social Text, 23(3-4), 219-233.

Hammersley, M., \& Atkinson, P. (2007). Ethnography: Principles in practice. Londres: Routledge.

Huq, R. (2006). Beyond subculture. Pop, youth and identity in a postcolonial world. Nova Iorque: Routledge.

Luzia de Abreu, C. (2012). Non-heteronormative genders in Web 2.0. Em S. M. da Silva, 
\& P. Landri (Eds.), Rethinking education ethnography. Researching on-line communities and interactions (pp. 27-32). Porto: Centro de Investigação e Intervenção Educativas.

Maia, J., \& Bianchi, E. (2008). Tecnologia de geolocalização: Grindr e Scruff redes geosociais gays. Logos: Comunicação e Universidade, 15(2), 19-29.

Menezes, I. (2000). Intimidade, norma e diferença: A modernidade gay em Lisboa. Análise Social, XXXIV(153), 933-955.

Miceli, M. S. (2002). "Gay, lesbian and bisexual youth". Em D. Richardson, \& S. Seidman (Eds.), Handbook of lesbian E gay studies (pp. 199-214). Londres: Sage Publications.

Miskolci, R. (2013). Machos e brothers: Uma etnografia sobre o armário em relações homoeróticas masculinas criadas on-line. Estudos Feministas, 21(1), 301-324.

Miskolci, R. (2015). “Discreto e fora do meio" - Notas sobre a visibilidade sexual contemporânea. Cadernos Pagu, (44), 61-90. doi: 10.1590/1809-4449201500440061

Pais, J. M. (2005). Jovens e cidadania. Sociologia, Problemas e Práticas, (49), 53-70.

Pink, S. (2013). Doing visual ethnography. Londres: Sage.

Pullen, C., \& Cooper, M. (2010). LGBT identity and online new media. Nova Iorque: Routledge.

Rooke, A. (2010). Queer in the field. On emotions, temporality and performativity in ethnography. Em K. Browne, \& C. Nash (Eds.), Queer methods and methodologies. Intersecting queer theories and social science research (pp. 25-39). Farnham: Ashgate.

Silva, S. M. da (2011). Da casa da juventude aos confins do mundo. Etnografia das fragilidades, medos e estratégias juvenis. Porto: Edições Afrontamento.

Stoer, S., \& Magalhães, A. (2005). 'A diferença somos nós'. A gestão da mudança social e as politicas educativas e sociais. Porto: Edições Afrontamento.

Valentine, G., \& Skelton, T. (2003). Finding oneself, losing oneself: The lesbian and gay 'scene' as a paradoxical space. International Journal of Urban and Regional Research, 27(4), 849-866.

Data de submissão: 23/06/2019 | Data de aceitação: 25/10/2019 